\title{
Análise da produção científica sobre mídias sociais e bibliotecas nos periódicos da Ciência da Informação no Brasil ${ }^{1}$
}

\author{
Maira Nani França \\ Doutoranda; Universidade Estadual Paulista, Marília, SP, Brasil; \\ mairanani@hotmail.com \\ Angela Maria Grossi de Carvalho \\ Doutora; Universidade Estadual Paulista, Marília, SP, Brasil; \\ angela.grossi@unesp.br
}

\begin{abstract}
Resumo: As mídias sociais se inserem na vida de grande parte da sociedade ao redor do mundo, nos mais diversos segmentos, impactando a forma de agir, pensar e se relacionar dos sujeitos. Às bibliotecas, como organizações responsáveis por disponibilizar acesso à informação, ao conhecimento e à aprendizagem, é imprescindível o acompanhamento das mudanças sociais e transformações tecnológicas, para que possam cumprir o seu papel na sociedade contemporânea. Neste contexto, com esta pesquisa busca-se identificar as características da produção científica brasileira sobre mídias sociais e bibliotecas de modo a acompanhar sua evolução e apontar tendências. Trata-se de um estudo descritivo, de natureza qualiquantitativa, fundamentado na análise de domínio, proposta por Hjørland. O universo da pesquisa é constituído por 54 artigos publicados em periódicos científicos nacionais da Ciência da Informação. Constatou-se que o domínio analisado tem sido discutido pela comunidade científica desde 2007, principalmente no âmbito das bibliotecas universitárias. A maioria dos autores citantes e citados pertence à Ciência da Informação, em colaboração com pesquisadores da Comunicação Social e Sociologia. Identificou-se o estágio inicial de formação de uma comunidade epistêmica na Ciência da Informação. Redes sociais tem sido a terminologia comumente adotada pelos pesquisadores da área para representar os ambientes de comunicação mediados pelo computador; embora, o termo mídias sociais tenha conquistado um espaço de destaque nos últimos anos. Identificaram-se novos léxicos no domínio analisado, para possível atualização dos esquemas de organização e representação do conhecimento produzido no país, no campo da Ciência da Informação.
\end{abstract}

Palavras-chave: Redes sociais. Mídias sociais. Biblioteca. Produção científica. Análise de domínio. 


\section{Mídias sociais e bibliotecas}

Apesar de o Brasil ocupar a $10^{\circ}$ posição no ranking da desigualdade social conforme dados apresentados pelas Nações Unidas (DESENVOLVIMENTO..., 2017), são perceptíveis as alterações nos hábitos culturais da sociedade impactadas pela inserção da internet nas atividades cotidianas, sob influência direta da popularização dos dispositivos móveis e pelo uso das mídias sociais.

Em 2017, mais de 120 milhões de brasileiros acessavam a internet, representando $67 \%$ da população acima de dez anos de idade, sendo que quase a totalidade $(96 \%)$ destes usuários navegavam na grande rede mundial por meio de telefone celular, principalmente, para trocar mensagens (WhatsApp, Skype ou chat do Facebook) e para utilizar as mídias sociais, com destaque para Facebook e Twitter. Estas foram apontadas pelo Centro Regional de Estudos para o Desenvolvimento da Sociedade da Informação (Cetic.br) como as ferramentas mais utilizadas no país (PESQUISA..., 2018).

Nas últimas décadas, especificamente a partir de 1990, o avanço do conhecimento tecnológico e inovador se faz presente nas mais diversas áreas da sociedade e, consequentemente, nos principais grupos sociais: familiar, educativo, religioso, de lazer, profissional e político.

No contexto do desenvolvimento da indústria e da crescente concentração de pessoas nas cidades nos séculos XVIII e XIX, que contribuíram para um processo de profunda transformação social (MUELLER, 1984), surgem as bibliotecas públicas, instituições sociais que, desde então, visam atender a propósitos sociais, como educação, lazer, cultura e informação.

A partir de 2004, a inserção dos conceitos de redes sociais, comunidade, colaboração e participação no âmbito das bibliotecas, sustentados no conceito da Web 2.0, tem impactado tanto no aperfeiçoamento/criação de serviços e produtos informacionais quanto nas novas oportunidades de relacionamento com os usuários.

Evidências empíricas nacionais e internacionais ratificam a inserção das mídias sociais no contexto das bibliotecas e a preocupação dos pesquisadores em conhecer e compreender o impacto deste fenômeno, a fim de buscar os melhores 
caminhos para lidar com ele em prol das experiências de crescimento social e cognitivo.

Dentre as investigações sobre mídias sociais no contexto das bibliotecas, destaca-se o estudo sobre o uso dos recursos da Web 2.0 nas bibliotecas universitárias espanholas. Em 2012, Herrara Morillas e Castillo Díaz analisaram que o uso desses recursos era bastante incipiente, de modo limitado, pautado em um planejamento mais informativo do que relacional, embora 90,4\% das bibliotecas já os aplicassem (OPAC 2.0, Facebook, Twitter, blogs, RSS). Especificamente sobre as mídias sociais, os autores afirmam que a partir de 2012 o uso do Twitter começava a se estender, enquanto o Facebook continuava sendo a ferramenta mais adotada, com a incorporação nestes ambientes informacionais digitais, por parte das bibliotecas, a mais de um ano. Nesse sentido, os autores recomendam que as bibliotecas "explorem o potencial de interação com o público que essas ferramentas podem fornecer e, de forma subsidiária, as utilizem para gerenciar e promover sua imagem e reputação no contexto online" (HERRARA MORILLAS; CASTILLO DÍAZ, 2012, p. 197, tradução nossa e grifo nosso).

Um ano depois, Baro, Ebiagbe e Godfrey (2013), ao compararem o uso das ferramentas da Web 2.0 pelos bibliotecários das bibliotecas universitárias da Nigéria e da África do Sul, concluíram que os profissionais da África do Sul se apropriaram mais desses recursos em relação aos da Nigéria, provavelmente pela falta de conscientização, desinteresse, desconhecimento e problemas de infraestrutura. Ratificando o resultado encontrado na pesquisa de Herrara Morillas e Castillo Díaz (2012), o Facebook é a mídia social mais utilizada pela comunidade acadêmica dos dois países, seguido pelo Twitter. A partir dos resultados encontrados, os autores recomendam que a) as bibliotecas da Nigéria forneçam fontes de energia estáveis; b) os cursos de biblioteconomia providenciem a atualização curricular incorporando conteúdo relacionado aos recursos da Web 2.0; c) as entidades de classe promovam cursos de capacitação e atualização e d) os gestores das bibliotecas disponibilizem os recursos necessários (físicos e tecnológicos) para a comunidade acadêmica utilizar as ferramentas da Web 2.0 (BARO; EBIAGBE; GODFREY, 2013). 
Preocupados em refletir sobre o uso de uma plataforma para aprimorar o envolvimento dos usuários com a biblioteca, Shafawi e Hassan (2018) investigaram os fatores que impulsionam o engajamento em bibliotecas na Malásia, apontado pelos autores como uma das principais medidas de sucesso de uma mídia social. "Através da participação das mídias sociais da biblioteca, a probabilidade de utilização da biblioteca aumentará." (SHAFAWI; HASSAN, 2018, p. 29, tradução nossa). Apesar da predominância do uso das mídias sociais, preferencialmente Youtube, Facebook e Twitter, os autores identificaram uma baixa taxa de engajamento por parte dos usuários, atribuída à falta de divulgação da existência desses recursos como mais um canal de informação e comunicação da biblioteca, interação passiva entre bibliotecários e usuários e postagem de conteúdo que não são de interesse. Neste sentido, a qualidade da informação, a interatividade e os benefícios percebidos são indicados como um relevante presságio de engajamento de usuários com as mídias sociais da biblioteca (SHAFAWI; HASSAN, 2018).

Complementando os dados acima apresentados, de modo a contribuir com a análise do comportamento da Ciência no campo da Ciência da Informação, propõese com este estudo identificar as características da produção científica brasileira sobre o fenômeno informacional em questão, no contexto em que se materializa, bem como acompanhar sua evolução e apontar tendências.

\section{Trajetória metodológica}

Trata-se de uma pesquisa em organização do conhecimento de natureza básica; descritiva, quanto aos objetivos, e bibliográfica, quanto aos procedimentos técnicos (SILVA; MENEZES, 2005), desenvolvida a partir de algumas das abordagens da análise de domínio propostas por Hjørland (2002): a) estudos históricos; b) estudos epistemológicos e críticos; c) estudos terminológicos; d) estudos bibliométricos e e) classificações especiais e tesauro.

Por meio dos estudos históricos, buscou-se identificar a origem e inserção da temática mídias sociais e bibliotecas na Ciência da Informação. Pelos estudos epistemológicos/críticos, foram investigadas as correntes filosóficas, paradigmas, 
teorias, métodos de pesquisa e análise adotadas no domínio em questão. A identificação da terminologia empregada pela comunidade discursiva para representar os ambientes de interação mediada pelo computador pautou-se nos estudos terminológicos. Por intermédio dos estudos bibliométricos, buscou-se conhecer indicadores de produção (autores mais produtivos, número de publicações, tipos de autorias, área de formação); os autores nacionais e internacionais que constituem a frente de pesquisa na área ou em áreas correlatas e a comunidade epistêmica. Além disso, a análise das citações e suas diferentes relações contribuiu na identificação das influências epistemológicas, metodológicas e teóricas do domínio investigado. Finalizando, por meio de classificações especiais e tesauros, o universo analisado foi categorizado, o que permitiu identificar as brechas (gaps) referentes ao objeto de estudo e contribuir com o aprimoramento dos esquemas de representação para organização do conhecimento já existentes na CI (HJØRLAND, 2002).

O levantamento foi realizado na Base de Dados Referenciais de Artigos de Periódicos em Ciência da Informação (BRAPCI) ${ }^{2}$, no segundo semestre de 2018, a partir dos descritores: rede social; mídia social e suas variações no plural, Web social e Web 2.0 associados ao termo biblioteca, considerando o período de $1972^{3}$ a 2017 como delimitação temporal. A BRAPCI disponibiliza acesso a mais de vinte mil documentos publicados em 57 periódicos nacionais, anais de eventos, livros, entre outros. Adotou-se como critérios de exclusão: a) títulos repetidos; b) determinados tipos de documentos, como trabalhos publicados em anais de evento, resenhas, editoriais, trabalhos de conclusão de curso, documento (dossiê de evento) e entrevista; c) assuntos não pertinentes à temática central da pesquisa (mídias sociais e bibliotecas) e; d) artigos não disponíveis online $e^{4}$.

A partir dessa busca, foram recuperados 211 artigos, que após análise do título, resumo e palavras-chave, bem como aplicação dos critérios de exclusão, obteve-se um total de 54 documentos (25,59\%), englobando artigos científicos, artigos científicos temáticos, relatos de experiência, revisão de literatura e comunicação ${ }^{5}$, assinados por 123 autores (autoria e coautoria).

Para definição da vinculação institucional (afiliação) dos autores que citam (citantes) considerou-se a instituição que abriga o programa de pós-graduação em 
que a pesquisa foi desenvolvida. O perfil (nacionalidade e grau de formação superior) dos pesquisadores citantes e dos mais citados foi elaborado a partir do respectivo currículo disponível na Plataforma Lattes, para autores nacionais e, para os autores estrangeiros, na rede social de negócios LinkedIn e/ou endereços eletrônicos das afiliações institucionais mencionadas nos artigos. Para se obter um tratamento mais equitativo e resultados mais refinados, optou-se pela normalização da identificação dos autores citantes (formação/área de atuação) usando o grau mais elevado de educação formal (graduação ou mestrado ou doutorado) ou estágio pósdoutoral. Para normalização dos citados decidiu-se pelo primeiro grau de formação. Em ambos os casos, adotou a Tabela de áreas do conhecimento/avaliação (BRASIL, 2017) da Coordenadoria de Aperfeiçoamento de Pessoal de Nível Superior (Capes) para padronização da área de atuação/formação dos pesquisadores. Tanto para os citantes quanto para citados, quando o autor apresentou mais de um título no mesmo grau, optou-se por aquele mais próximo à Ciência da Informação ou à grande área das Ciências Sociais Aplicadas.

Para melhor identificar o modo como o conhecimento científico em mídias sociais e bibliotecas foi construído e socializado, realizou-se análise de citação (estudos bibliométricos) nos 54 artigos selecionados. Foram consideradas todas as referências que no campo Indicação de responsabilidade apresentavam entrada apenas de autores pessoa física, com ou sem indicação explícita de responsabilidade pelo conjunto da obra (organizadores, editores etc.), incluindo autocitações e referências com mais de três autores que adotaram a expressão latina et al. (do latim et alii, e outros). Neste caso, foi realizada uma pesquisa prévia na fonte original para identificação de todos os coautores. As obras elaboradas por pessoa jurídica, advindas de eventos ou que apresentaram autoria desconhecida (entrada pelo título) não foram incluídas na análise.

No corpus de análise, tratando-se especificamente dos autores citados, identificou-se que 952 pesquisadores foram referenciados, dos quais $774(81,3 \%)$ foram mencionados apenas uma vez. Para seleção daqueles mais citados, a fim de compor o universo de análise, aplicou-se a Lei do Elitismo ${ }^{6}$, proposta pelo cientista da informação Solla Price, em que a raiz quadrada do número total de colaboradores em um determinado domínio representa a elite da área estudada 
(URBIZAGÁSTEGUI ALVARADO, 2009). Por aproximação, pela aplicação desta lei, foram identificados 32 pesquisadores dentre os mais citados, em pelo menos cinco artigos; sendo a raiz quadrada de 952, aproximadamente 30, englobando neste conjunto os pesquisadores com o mesmo número de produções científicas, próximo ao valor desta raiz.

Finalizando, com ênfase na abordagem classificações especiais e tesauros de Hjørland (2002), buscou-se organizar o conhecimento produzido na temática analisada em categorias a partir de dois instrumentos de representação da Ciência da Informação: a) categorização do contexto de abordagens das Tecnologias da Informação e Comunicação (TIC) nos trabalhos publicados pela CI: teoria, desenvolvimento, uso, avaliação, políticas, ética (SANTOS et al., 2013, p. 3) e competência em informação (FRANÇA; CARVALHO; GRÁCIO, 2018, p. 363), e b) ordem sistemática do Tesauro Brasileiro da Ciência da Informação (TBCI) do IBICT (PINHEIRO; FERREZ, 2014), principalmente a seção 1 que trata da Epistemologia da Ciência da Informação.

\section{Resultados: apresentação e análise}

Dos 19.255 trabalhos publicados em revistas científicas brasileiras da Ciência da Informação - indexadas pela BRAPCI, de 1972 a 2017 -, obteve-se um total de 54 artigos, o que corresponde a $0,28 \%$ do universo pesquisado, selecionados como corpus de análise.

Os primeiros estudos sobre mídias sociais e bibliotecas surgem na produção científica nacional a partir de 2007, três anos após o empresário e entusiasta da internet, Tim O'Reilly, ter concebido o conceito de Web 2.0. A evolução da produção científica sobre o tema em questão pode ser observada no Gráfico 1, sob uma perspectiva diacrônica, com os maiores índices registrados em 2012 e 2016 e queda considerável, respectivamente, em 2013 e 2017. 


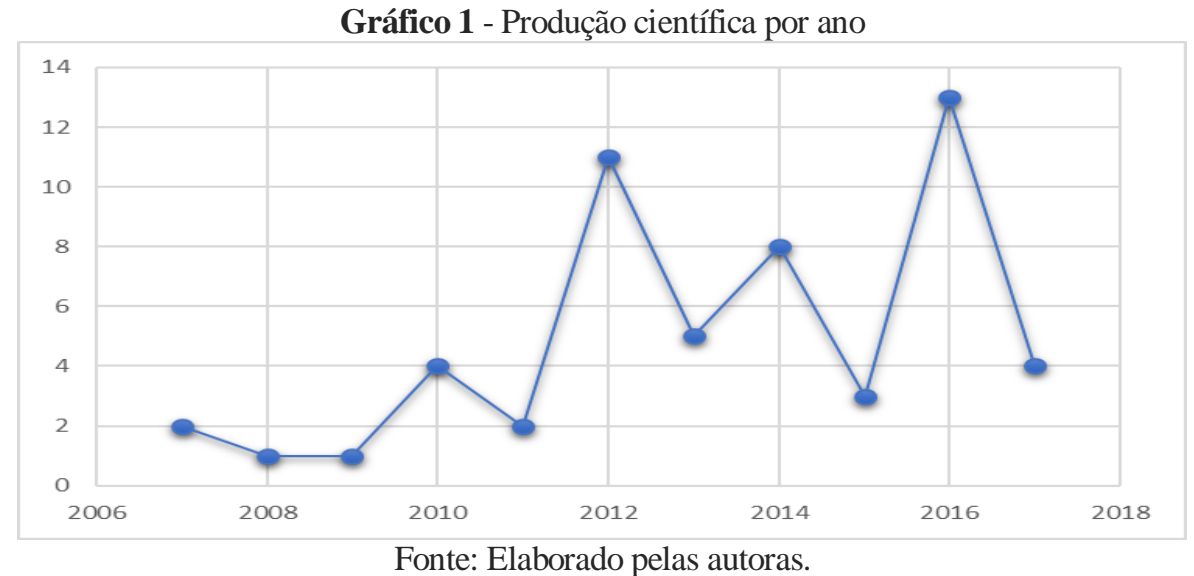

Pelos resultados apresentados no Gráfico 2, é possível verificar que a temática analisada tem sido discutida em $40 \%$ das publicações periódicas indexadas na BRAPCI, sendo possível delimitar o seu alcance e sua relevância na Ciência da Informação.

Gráfico 2 - Periódicos científicos da CI que publicam a temática analisada

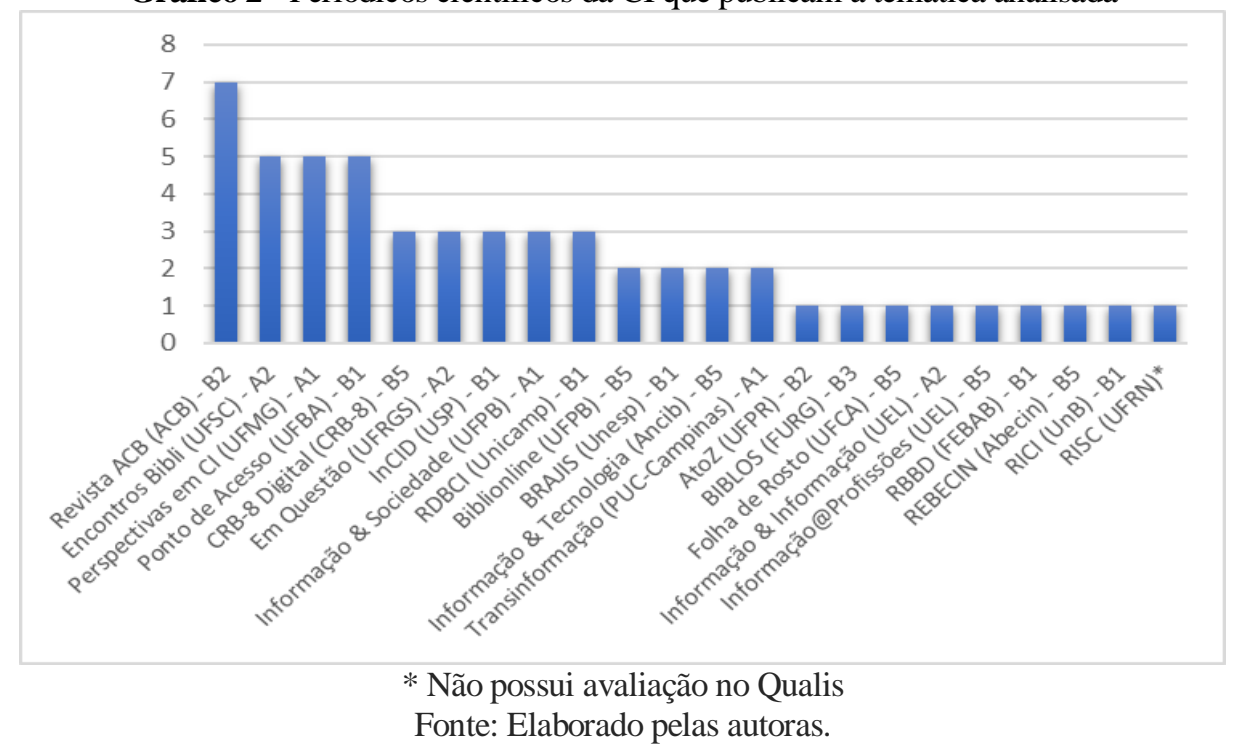

Neste sentido, dentre os periódicos que mais publicam artigos sobre mídias sociais e bibliotecas, destacam-se a) Revista ACB: Biblioteconomia em Santa Catarina da Associação Catarinense de Bibliotecários (ACB, São José, SC); b) Encontros Bibli: Revista Eletrônica de Biblioteconomia e Ciência da Informação da Universidade Federal de Santa Catarina (UFSC, Florianópolis, SC), c) Perspectivas em Ciência da Informação da Universidade Federal de Minas Gerais (UFMG, Belo Horizonte, MG) e d) Ponto de Acesso da Universidade Federal da 
Bahia (UFBA, Salvador, BA), que publicaram, nestes últimos dez anos, pelo menos cinco artigos cada.

Cabe ressaltar que a maioria dos periódicos $(54,4 \%)$ se enquadra nos estratos de A1 a B1, da classificação Qualis-Periódicos (BRASIL, [2018]) da Capes, sendo $13,6 \%$ no A1; $13,6 \%$ no A2 e 27,2\% no B1, evidenciando que a temática tem alcançado espaço de excelência no cenário científico nacional (Gráfico 2).

Na sequência são apresentados o perfil dos autores citantes (nacionalidade, tipo de autoria, afiliação e grau de formação superior e produtividade), os autores citados mais representativos na área (análise de citação), o conteúdo discutido e sua categorização.

\subsection{Análise dos autores que citam}

Em relação à formação dos 123 autores, nomeados nesta pesquisa de citantes, confirmou-se a hipótese de que a maioria $(82,9 \%)$ pertence à área da Ciência da Informação, considerando o âmbito de aplicação das pesquisas analisadas (bibliotecas). No entanto, ratificando a natureza interdisciplinar da área, também foram identificados pesquisadores de outras áreas do conhecimento, a saber: Ciências Sociais Aplicadas (Comunicação Social e Administração); Ciências Humanas (Sociologia); Linguística, Letras e Artes (Letras); Ciências Exatas e da Terra (Geociências) e Multidisciplinar (Interdisciplinar).

Apesar de a maioria dos citantes estar vinculada às instituições de ensino superior brasileiras $(86,9 \%)$, é possível afirmar que os periódicos científicos da área no Brasil têm ampliado o seu processo de internacionalização por meio da publicação de artigos de autoria de pesquisadores vinculados às instituições educacionais de outros países como Portugal ${ }^{7}$, Espanha $^{8}$, Estados Unidos $^{9}, \mathrm{Cuba}^{10} \mathrm{e}$ India ${ }^{11}$.

No Brasil, observa-se que a UFSC (12,1\%), a Universidade de Brasília (UnB) (12,1\%), a Universidade do Estado de Santa Catarina (UDESC) (9,3\%), a UFBA $(8,4 \%)$ e a Universidade Federal da Paraíba (UFPB) $(6,5 \%)$ destacam-se por 
possuírem o maior número de colaboradores que desenvolvem pesquisas no domínio analisado, com pelo menos uma publicação nos últimos três anos (20152017) (Gráfico 3).

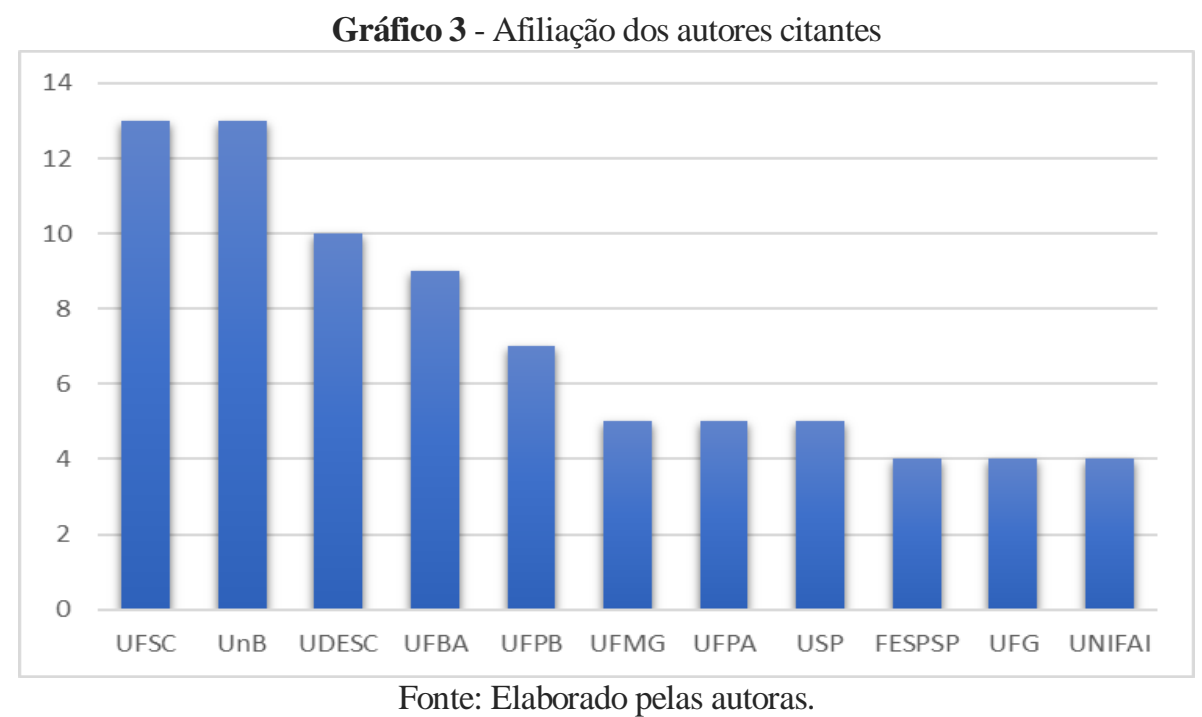

Em relação aos percentuais por tipo de autoria presentes na produção científica analisada, observa-se a prevalência das publicações em coautoria, correspondendo a 83,3\%, evidenciando a presença de colaboração científica na temática (Gráfico 4). O número de trabalhos com autoria dupla é o mais frequente (44,4\%), apresentando predominância desde 2007, com exceção nos anos de 20082009 e 2015. Em 2012, foram publicados os artigos de autoria quádrupla e, em 2015, o de quíntupla.

Gráfico 4 - Tipos de autoria presentes na produção científica analisada

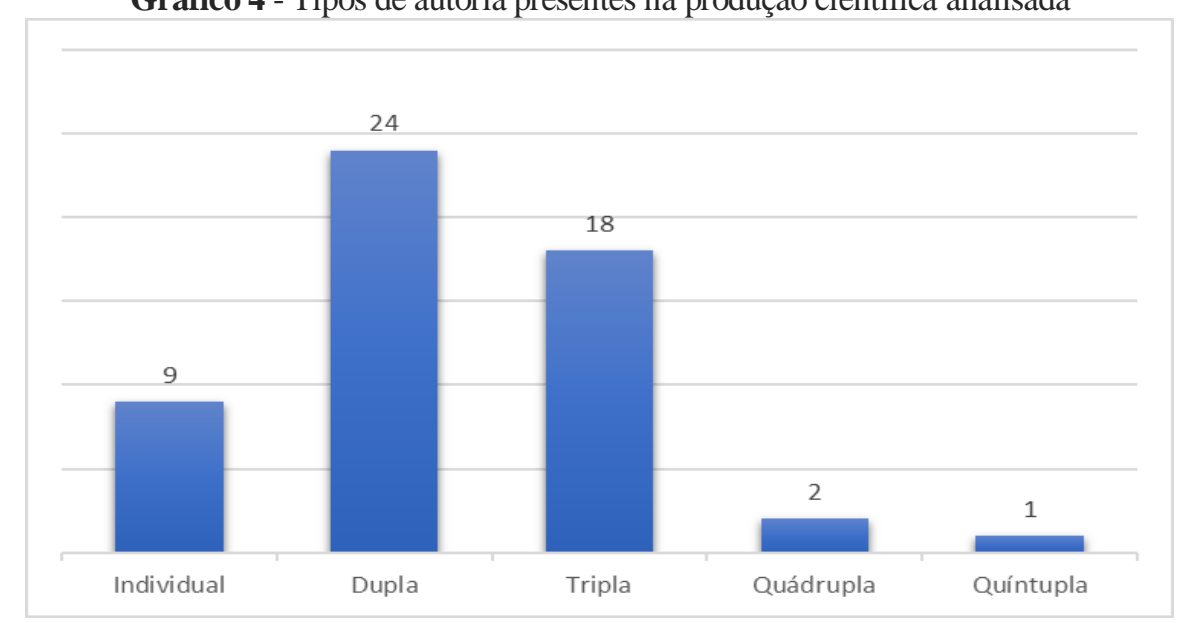

Fonte: Elaborado pelas autoras. 
Os 15 autores com o maior número de publicações na temática analisada (Gráfico 5) são responsáveis por pelo menos dois trabalhos publicados, sendo alguns deles de autoria individual.

Gráfico 5 - Autores citantes mais representativos

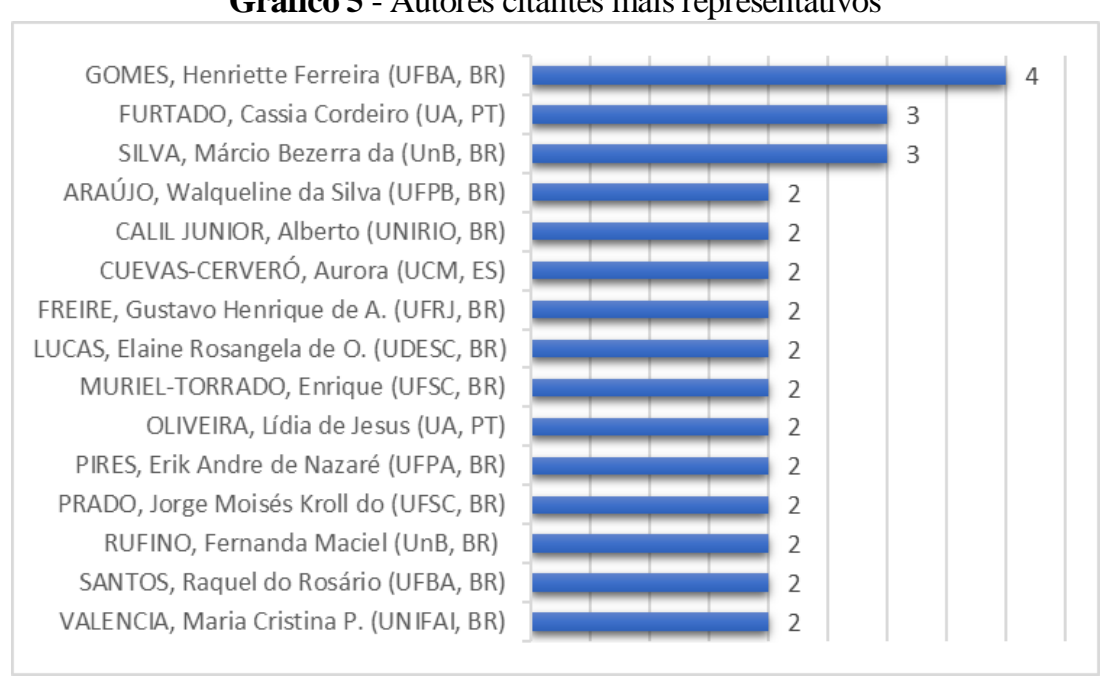

Fonte: Elaborado pelas autoras.

Estes pesquisadores, que representam $27,6 \%$ do total de autores responsáveis pelo conjunto dos trabalhos analisados, possuem formação na área de Ciências Sociais Aplicadas (Ciência da Informação e Comunicação Social) e vínculo com instituições de pesquisa no Brasil (UFBA, UnB, UFPB, Universidade Federal do Estado do Rio de Janeiro - UNIRIO, Universidade Federal do Estado do Rio de Janeiro - UFRJ, UDESC, UFSC, Universidade Federal do Pará - UFPA, Centro Universitário Assunção - UNIFAI), em Portugal (Universidade de Aveiro) e na Espanha (Universidade Complutense de Madrid) (Gráfico 5).

Na próxima seção, serão apresentados e discutidos o perfil dos autores citados pelos 123 autores citantes.

\subsection{Análise dos autores citados}

Os autores mais citados nos artigos analisados foram classificados pelo número de citações recebidas. Pela aplicação da Lei do Elitismo, obteve-se um total de 32 autores citados em pelo menos cinco, dos 54 artigos analisados, apresentados em 
ordem decrescente no Quadro 1. Os pesquisadores citados em mais artigos foram Jack Maness, professor estadunidense da University of Denver Libraries (21) e Ursula Blattmann, bibliotecária brasileira e docente da UFSC (19).

Quadro 1 - Autores citados em pelo menos cinco artigos

\begin{tabular}{||l|c||l|c||}
\hline \multicolumn{1}{|c|}{ Autores citados } & $\begin{array}{c}\mathbf{N}^{\mathbf{0}} \text { de } \\
\text { artigos }\end{array}$ & \multicolumn{1}{|c||}{ Autores citados } & $\begin{array}{c}\mathbf{N}^{\mathbf{0}} \text { de } \\
\text { artigos }\end{array}$ \\
\hline Maness, Jack (USA) & 21 & Amaral, Sueli Angélica do (BR) & 6 \\
\hline Blattmann, Ursula (BR) & 19 & Calil Junior, Alberto (BR) & 6 \\
\hline O’Reilly, Tim (IRL) & 18 & Stephens, Michael (USA) & 6 \\
\hline Cunha, Murilo Bastos da (BR) & 16 & Almeida júnior, Oswaldo F. de (BR) & 5 \\
\hline Silva, Fabiano Couto Corrêa da (BR) & 16 & Alvim, Luísa (PT) & 5 \\
\hline Recuero, Raquel (BR) & 13 & Andrade, António Manuel V. de (PT) & 5 \\
\hline Castells, Manuel (ESP) & 11 & Corrêa, Elisa Cristina Delfini (BR) & 5 \\
\hline Casey, Michael E (USA) & 9 & Di Chiara, Ivone Guerreiro (BR) & 5 \\
\hline Tomaél, Maria Inês (BR) & 9 & Gil, Antônio Carlos (BR) & 5 \\
\hline Cavalcanti, Cordélia R. de O. (BR) & 8 & Gomes, Henriette Ferreira (BR) & 5 \\
\hline Marteleto, Regina Maria (BR) & 8 & Kumar, Sunil (IN) & 5 \\
\hline Jesus, Deise Lourenço de (BR) & 7 & Lakatos, Eva Maria (BR) & 5 \\
\hline Lévy, Pierre (TUN) & 7 & Marconi, Marina de Andrade (BR) & 5 \\
\hline Margaix-Arnal, Dídac (ESP) & 7 & Milanesi, Luiz Augusto (BR) & 5 \\
\hline Vieira, David Vernon (BR) & 7 & Miller, Paul (GB) & 5 \\
\hline Alcará, Adriana Rosecler (BR) & 6 & Tripathi, Manorama (IN) & 5 \\
\hline \hline
\end{tabular}

Fonte: Elaborado pelas autoras.

Também se destacam, na Ciência da Informação brasileira, os bibliotecários e docentes Murilo Bastos da Cunha, vinculado ao PPGCI da UnB, e Fabiano Couto Corrêa da Silva, vinculado à Universidade Federal do Rio Grande (FURG), ambos mencionados em 16 artigos. O irlandês Tim O'Reilly, criador da expressão Web 2.0, também se encontra entre os autores mais citados, sendo referenciado em 18 artigos e, ainda, a pesquisadora brasileira no campo da Comunicação, Raquel Recuero (13) e o sociólogo espanhol, Manuel Castells (11) (Quadro 1).

Ressalta-se ainda que apenas quatro artigos $(7,4 \%)$ não mencionaram nenhum dos pesquisadores considerados o núcleo da literatura científica na temática do domínio analisado, o que reforça a visibilidade e o reconhecimento do grupo de autores listados no Quadro 1. No entanto, apesar desses artigos não mencionarem os autores mais citados, eles apresentam relação direta com esta pesquisa por 
discutirem as possibilidades de potencialização dos hábitos de leitura e da função educativa das bibliotecas por meio das ferramentas participativas da Web social.

A bibliotecária e professora Cordélia Robalinho de Oliveira Cavalcanti, que faleceu em abril de 2017, deixou dentre os diversos legados para a biblioteconomia no país, a obra Dicionário de Biblioteconomia e Arquivologia (Ed. Briquet de Lemos, 2008) - mencionada em oito dos artigos analisados -, elaborada em coautoria com o professor Murilo Bastos da Cunha (Quadro 1). Outro resultado encontrado foi a inclusão dos principais teóricos brasileiros da metodologia científica no país, como Antônio Carlos Gil, Eva Lakatos e Marina Marconi, no núcleo da produção científica da Ciência da Informação analisada, ratificando a assertiva de Smiraglia (2011), em que estudos desta natureza apontam as tendências teóricas e/ou metodológicas de uma comunidade de pesquisa.

Em relação à origem dos autores mais citados, em âmbito internacional, destacam-se países como Estados Unidos, Irlanda, Espanha, Tunísia, Portugal, Reino Unido e Índia. Mesmo tratando-se de pesquisa realizada em publicações periódicas do Brasil, os dados apontam o predomínio (62,5\%) e, consequentemente, a visibilidade dos pesquisadores brasileiros na temática analisada. Quanto ao grau de formação superior, a maioria dos citados graduou-se em Biblioteconomia (62,5\%), resultado semelhante ao encontrado no grupo dos autores citantes, com contribuição de autores graduados em Comunicação Social e Economia também pertencentes a área das Ciências Sociais Aplicadas. Também foram identificados autores com formação em Letras e Linguística (Linguística, Letras e Artes); Arqueologia, Filosofia e História (Ciências Humanas) e Ciência da Computação (Ciências Exatas e da Terra), ratificando o campo interdisciplinar da Ciência da Informação.

Ao analisar esta variável, percebeu-se que independentemente das diversas formações (graduação), os autores adotam o referencial da área em que atuam, não levando, aparentemente, seu referencial original de formação para a área de atuação. Como exemplo, destaca-se Manuel Castells que se graduou em Direito e Economia e é reconhecido como sociólogo, título adquirido em seu mestrado e doutorado. Outro caso semelhante é o do pesquisador Pierre Lévy que concluiu sua graduação em História, com mestrado em História da Ciência e Doutorado em Sociologia e Ciências da Informação e da Comunicação e é identificado como filósofo e pesquisador em Ciência da Informação e Comunicação (FRANÇA; CARVALHO; GRÁCIO, 2018, p. 357). 
Ao contrapor a elite dos citantes, composta por 15 pesquisadores dos artigos analisados aos 32 autores mais citados, é possível afirmar que, mesmo com uma produção científica relativamente recente (2007-2017), a Ciência da Informação possui uma comunidade epistêmica na temática mídias sociais e bibliotecas, em estágio inicial de formação, com destaque para os bibliotecários e docentes, Henriette Gomes (UFBA) e Alberto Calil Júnior (UNIRIO), conforme destacado no Quadro 1. Ou seja, estes pesquisadores ao mesmo tempo em que em publicam são reconhecidos pela comunidade científica. Ratificando este resultado, em estudo recente, França e Carvalho (2018) identificaram que Henriette Gomes foi a única pesquisadora apontada como da comunidade epistêmica no âmbito das edições do Encontro Nacional de Pesquisa em Ciência da Informação (ENANCIB) no domínio em questão.

\subsection{Conteúdo discutido e sua categorização}

Analisando as terminologias que têm sido comumente adotadas pela Ciência da Informação para representar os ambientes de interação mediada pelo computador, observou-se uma preferência pelo termo redes sociais $(36,6 \%)$, seguido respectivamente por Web 2.0 (27,6\%), mídias sociais (23,2\%) e Web Social $(12,5 \%)$, com destaque para a preponderância do uso combinado dos termos em um mesmo artigo, em 77,7\% dos casos. O Gráfico 6 indica que o termo redes sociais tem sido utilizado pela comunidade científica de 2007 a 2017, de forma ininterrupta. Embora o termo mídia social tenha sido adotado na literatura a partir de 2012, observou-se o uso do termo social media em artigos de 2008 e 2009.

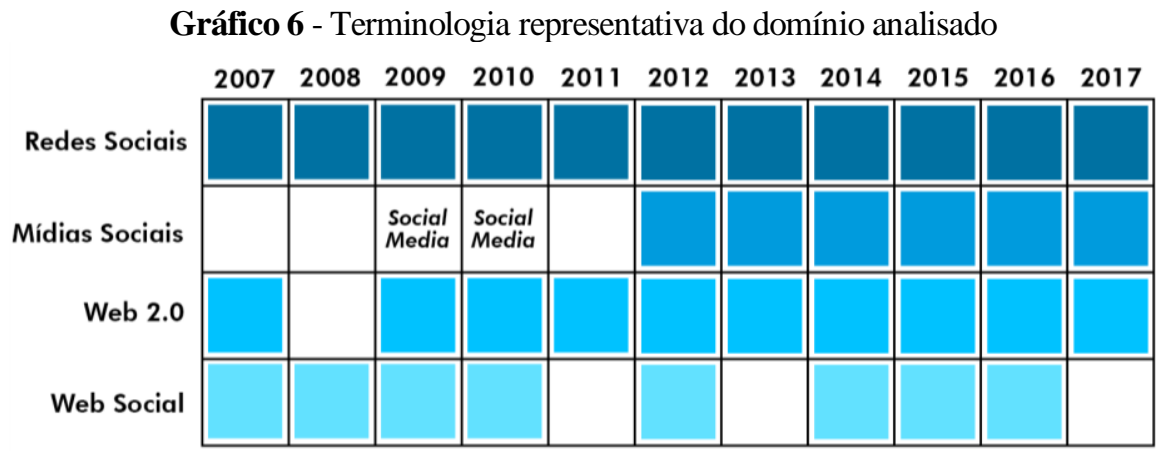

Fonte: Elaborado pelas autoras. 


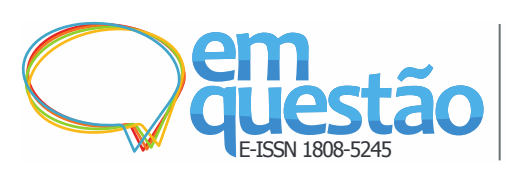

Também foram identificados outros descritores sinônimos, como ferramentas colaborativas, sites de relacionamento social, ferramentas sociais de tecnologia Web, plataformas sociais, dentre outros.

Quanto à forma dos termos, observou-se o predomínio do plural para os termos rede social e mídia social, corroborando um dos critérios de análise teóricoconceitual dos termos e sua seleção, adotado pelo TBCI (PINHEIRO; FERREZ, 2014). No referido documento, consta o registro apenas do descritor redes sociais, inserido na categoria 6.4 Sociedade da Informação do Plano Geral de Classificação (PINHEIRO; FERREZ, 2014, p. 264-265). Não foi identificada nenhuma menção aos termos Web 2.0, mídias sociais e Web social.

O dinamismo do contexto tecnológico e seus efeitos na terminologia permite indicar a necessidade de atualização dos instrumentos de representação e organização do conhecimento na Ciência da Informação, de modo a acompanhar a evolução da sociedade contemporânea e o seu reflexo no movimento da produção científica na temática analisada.

Ao avaliar o conteúdo dos artigos selecionados, identificou-se que nenhum deles menciona explicitamente as escolas ou correntes filosóficas e teorias da Ciência da Informação em que seus estudos estão amparados. Observa-se a adoção usual e genérica do termo paradigma no sentido de modelo, padrão a ser seguido, exemplificado nos seguintes trechos: novos paradigmas dessa sociedade, paradigmas da Web 2.0, paradigma da apropriação da informação, entre outros.

Poucos artigos explicitam como resultado de pesquisa os paradigmas científicos, conceito criado por Thomas Kuhn, interpretado como uma realização científica aplicada no campo filosófico, relacionado a epistemologia, tratando-se de um padrão que visa alcançar solução aos problemas em um mesmo sistema. Neste contexto, destaca-se o paradigma cartesiano, em que a divisão do todo em parte facilita a produção do conhecimento, citado em um dos artigos associado ao paradigma positivista. Ressalta-se também a menção ao paradigma tecnológico, conceito formulado por Giovanni Dosi em analogia ao paradigma científico defendido por Kuhn, a fim de entender as forças que movem o progresso tecnológico. Dos paradigmas epistemológicos da Ciência da Informação, descritos 
por Capurro (2003), identificou-se a associação do objeto de análise apenas ao paradigma social, em somente um trabalho.

Também foi observado exíguo aporte conceitual nos teóricos da Ciência da Informação, com destaque para Shiyali Ranganathan que introduziu a ideia de classificação facetada; Frederick W. Lancaster, com os estudos do desempenho das linguagens documentárias na recuperação da informação; Michael Buckland, com a teoria informação-como-coisa; Bernad Frohmann, com o conceito de regime de informação; Tefko Saracevic que defende o caráter interdisciplinar, tecnológico e social da Ciência da Informação e Jack Maness com a teoria da Biblioteca 2.0, questionada e interpretada por Campos (2007, p. 11) como "pertinentes postulados empíricos". O diálogo e as contribuições advindas das diferentes áreas do conhecimento ratifica o movimento interdisciplinar da Ciência da Informação, observado no domínio analisado pela apropriação da comunidade científica às proposições dos teóricos da Filosofia (Martin Heidegger, Marshall Berman, Regis Debray, Pierre Levy), Psicologia (Lev Vygotsky), História (Roger Chartier), Sociologia (Daniel Bell, Edgar Morin, Zigmunt Bauman, Pierre Boudier, Armand Mattelart, Anthony Giddens, Manuel Castells, Bruno Latour) e Comunicação Social (Henry Jenkins, Mauro Sá Martino, Raquel Recuero).

No corpus analisado, identificou-se que $50 \%$ dos artigos não apresenta uma seção específica para descrição da metodologia de pesquisa adotada e em alguns destes casos, quando o fazem, registram os procedimentos na introdução. Nenhum texto explicitou a natureza da pesquisa. Observou-se também que a minoria das pesquisas $(3,7 \%)$ menciona os pressupostos lógicos, ou seja, os métodos de abordagem, com destaque para os métodos empírico de John Locke (método indutivo) e fenomenológico de Edmund Husserl (fenomenologia). Ainda neste contexto, também se identificou a adoção do método comparativo de Edward Tylor e o método de funcionalista de Émile Durkheim, como métodos de procedimento $(3,7 \%)$.

Conforme sintetizado na Figura 1, os tipos de pesquisas aplicados nos estudos relacionados ao domínio analisado foram classificados quanto à: 
a) abordagem - qualiquantitativa (24\%), qualitativa $(9,3 \%)$, quantitativa $(9,3 \%)$ e não informado $(57,4 \%)$;

b) objetivos - exploratória $(18,5 \%)$, descritiva (13\%), descritiva-exploratória $(7,4 \%)$ e não informado $(61,1 \%)$;

c) procedimentos técnicos - bibliográfica (24\%), estudo de caso, incluindo o modelo de Robert Yin (14,8\%), bibliográfica e documental (13\%), documental $(3,7 \%)$, pesquisa com survey $(3,7 \%)$, pesquisa netnográfica $(1,9 \%)$ e não informado $(61,1 \%)$

d) levantamento/coleta de dados - observação (14,8\%), questionário $(11,1 \%)$, observação-questionário-entrevista $(5,6 \%)$, entrevista $(3,7 \%)$ e não informado $(64,8 \%)$;

e) tratamento/análise de dados - análise de conteúdo de Laurence Bardin (5,6\%), análise do conteúdo (1,9\%), análise estatística (1,9\%), análise combinatória $(1,9 \%)$, avaliação heurística de Jakob Nielsen $(1,9 \%)$ e não informado (87\%).

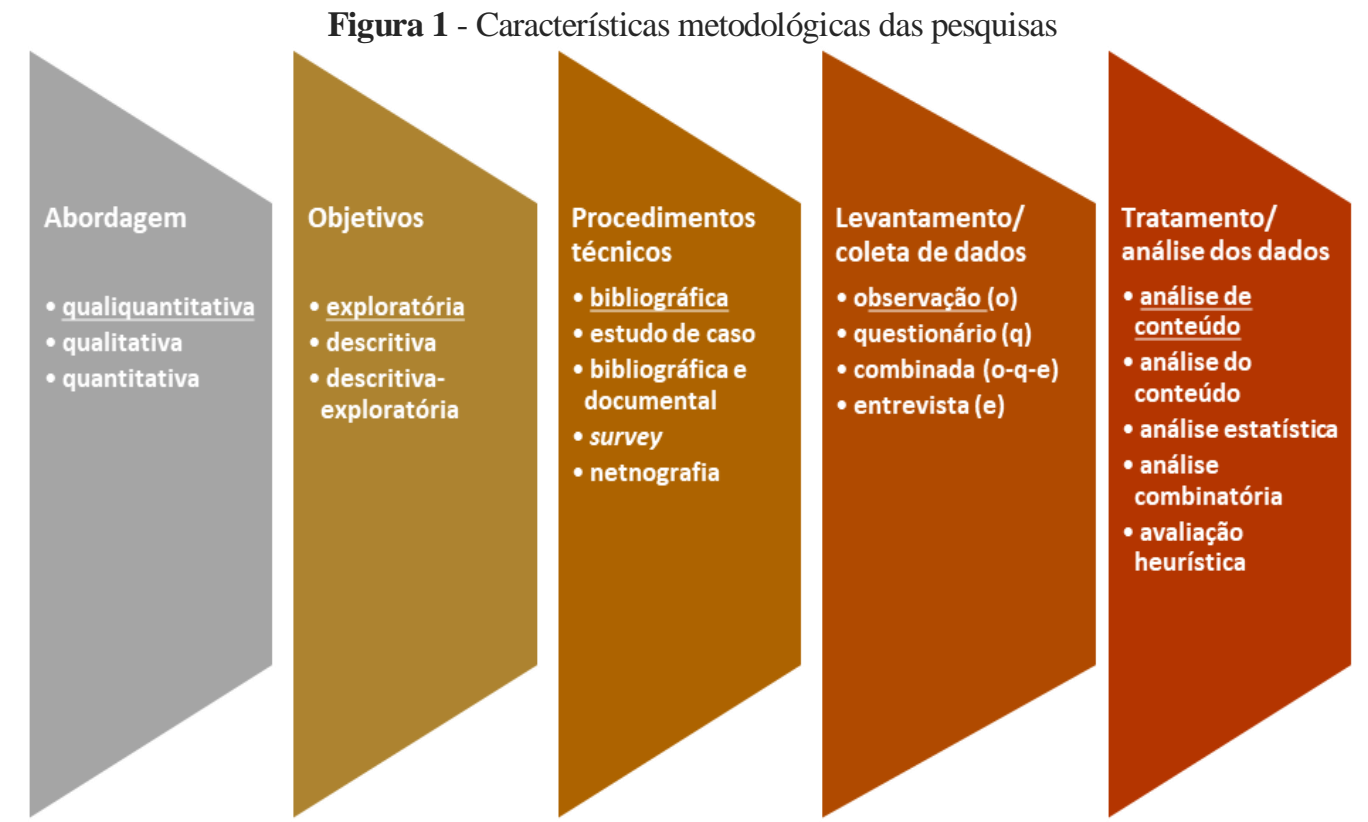

Obs.: Os tipos de pesquisa sublinhados foram os de maior ocorrência. Fonte: Elaborado pelas autoras.

A maioria dos trabalhos analisados investiga as mídias sociais em geral (76\%); no entanto, também foram identificados estudos aplicados em mídias sociais 
específicas, como Facebook, Youtube, Twitter, mídias sociais temáticas (ex. Biblon - rede social de leitores), dentre outras. Quanto à esfera de aplicação, é possível afirmar que pesquisas relacionadas à temática central analisada têm sido desenvolvidas preferencialmente nas bibliotecas universitárias (50\%), ratificando os resultados encontrados na pesquisa de França e Carvalho (2018). Também foram identificados estudos em bibliotecas em geral (25,9\%), bibliotecas públicas $(9,3 \%)$, bibliotecas escolares $(7,4 \%)$, bibliotecas nacionais $(5,6 \%)$ e bibliotecas especializadas (1,9\%) (Gráfico 7).

Gráfico 7 - Esfera de aplicação das pesquisas sobre mídias sociais e bibliotecas

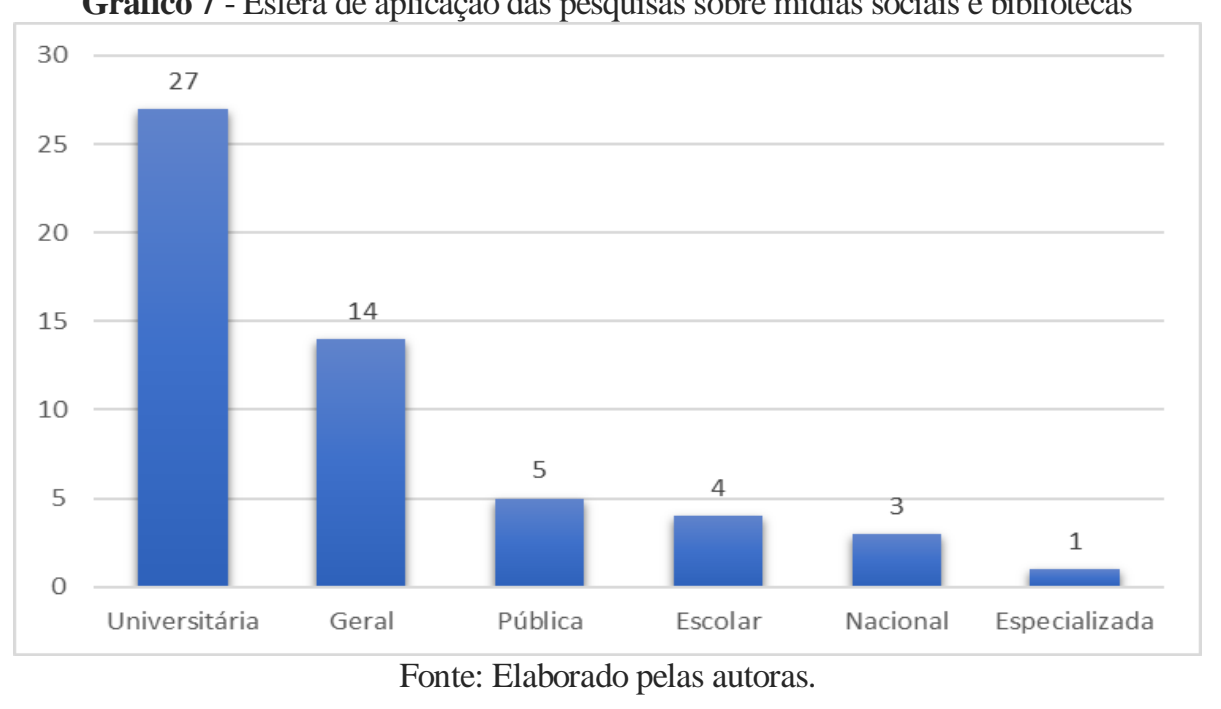

Não foi identificada nenhuma pesquisa sobre mídias sociais aplicadas em ambientes de informação digital; porém, conforme constatado por França e Carvalho (2018), ao realizarem estudos semelhantes nos trabalhos apresentados nas edições do ENANCIB, alguns pesquisadores no Brasil têm desenvolvido pesquisas sobre mídias sociais no contexto das bibliotecas digitais.

A partir das categorias propostas por Santos et al. (2013), ampliadas por França, Carvalho e Grácio (2018), a organização do conhecimento produzido na temática analisada permitiu identificar que a maioria dos trabalhos $(74,1 \%)$ se refere ao uso das mídias sociais em bibliotecas (serviços de bibliotecas, apropriação, marketing, promoção da leitura, serviços de orientação, disseminação da informação, automação de bibliotecas, preservação digital), seguido de 16,7\% que aborda questões teóricas (marketing, serviços de biblioteca, disseminação da 
Maira Nani França, Angela Maria Grossi de Carvalho

informação, serviços de orientação, redes sociais); 5,5\% que se enquadra na categoria competência em informação (alfabetização em informação e alfabetização em tecnologia da informação) e uma minoria que trata de desenvolvimento (programas de computador) $(1,8 \%)$ e questões políticas (políticas e ações de informação) $(1,8 \%)$, conforme apresentado no Gráfico 8. Não foi identificado nenhum artigo voltado para as questões éticas.

Gráfico 8 - Esfera de aplicação das pesquisas sobre mídias sociais e bibliotecas

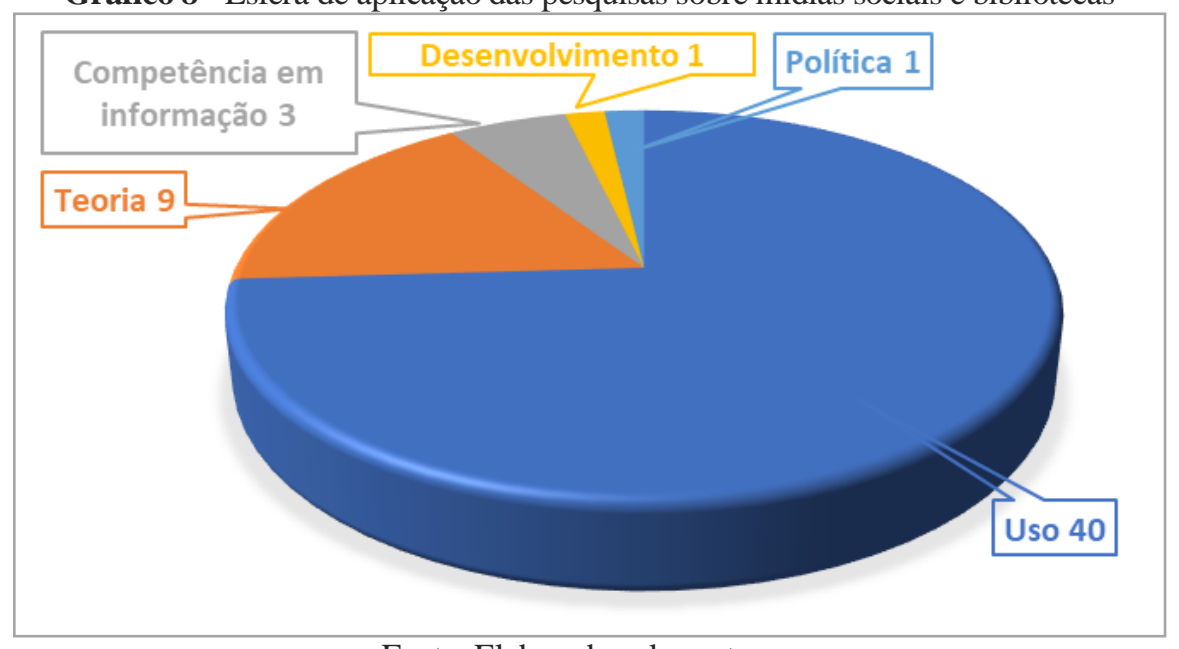

Fonte: Elaborado pelas autoras.

Finalizando, a partir da ordem sistemática do Tesauro Brasileiro da Ciência da Informação do IBICT (PINHEIRO; FERREZ, 2014), utilizada neste estudo para delinear o conteúdo que tem sido discutido no domínio analisado, os artigos foram classificados em:

a) 3.1 Gestão de bibliotecas e recursos de informação (marketing da informação, promoção do livro e da leitura) (20,4\%);

b) 3.1.1 Serviços de biblioteca (apropriação, marketing, disseminação) (37\%);

c) 3.3 Serviços de informação (disseminação da informação; orientação mediação) $(20,4 \%)$;

d) 5.2 Programas de computador $(1,8 \%)$;

e) 5.3 Aplicações de computador (automação de biblioteca) (1,8\%);

f) 5.5 Gestão nas TIC (preservação digital) $(1,8 \%)$;

g) 6.2.2 Políticas e ações de informação $(1,8 \%)$ e 
h) 6.4 Sociedade da informação (alfabetização em informação e em TI, redes sociais) $(14,8 \%)$, conforme indicado no Gráfico 9.

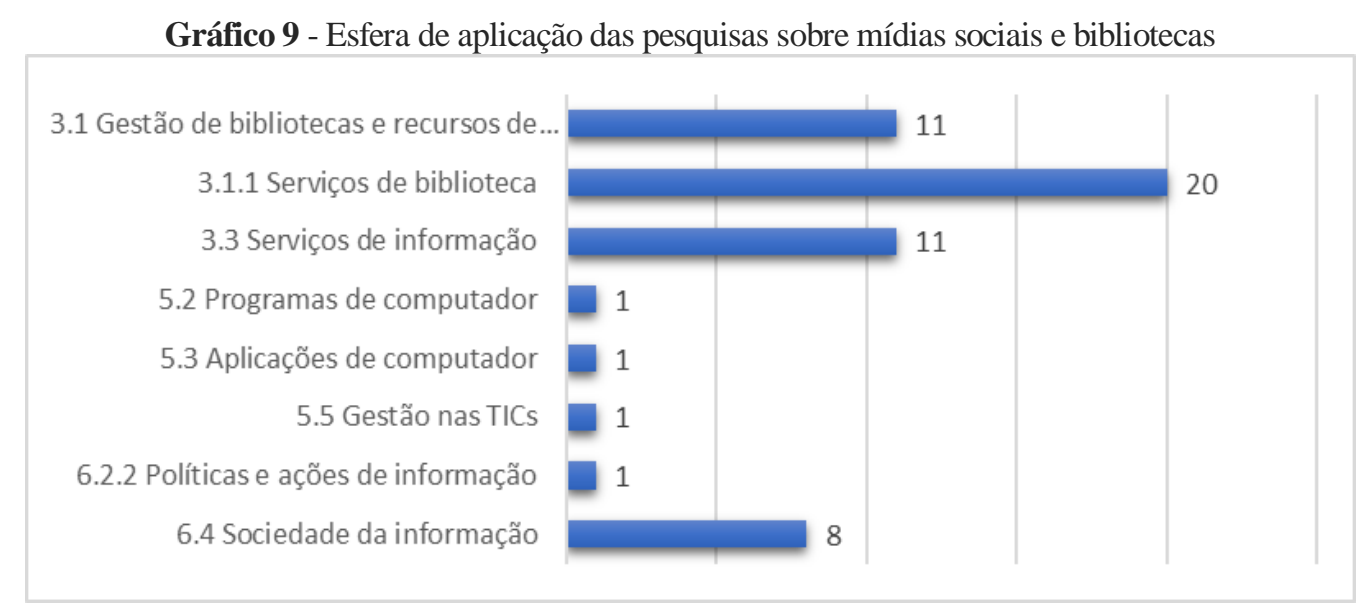

Fonte: Elaborado pelas autoras.

A categorização dos assuntos discutidos nos artigos analisados permitiu a identificação de novos termos que representam o domínio em estudo, para aprimoramento da representação de conceitos ainda não contemplados no Tesauro do IBICT, como mídias sociais, Web social, Web 2.0, capital social, apropriação, mediação da informação, marketing digital e/ou social media marketing, tecnologias sociais, dentre outros ${ }^{12}$. Os resultados encontrados, a partir do mapeamento do domínio analisado apontam, além das novas tendências da sociedade contemporânea, a não cobertura de determinados descritores sinalizados pela comunidade discursiva ou a falta de abrangência na cobertura de outros.

\section{Considerações finais}

Desde 2007, o domínio mídias sociais e bibliotecas tem sido discutido na literatura científica nacional em $40 \%$ das publicações periódicas indexadas na BRAPCI, com destaque para o ano de 2016, em que foi registrado o maior índice de produtividade. A relevância desta pesquisa apoia-se na originalidade de uma temática emergente ainda pouco explorada pela Ciência da Informação, correspondendo a 0,28\% do universo analisado. 
Confrontando a formação dos autores citantes com a dos autores citados conclui-se que, embora a maioria dos pesquisadores pertença à Ciência da Informação, identifica-se a relação interdisciplinar desta disciplina teórica com outras áreas do conhecimento, com destaque para a Comunicação Social e a Sociologia, ratificando a hipótese de que os pesquisadores da Ciência da Informação fundamentam-se predominantemente nesses campos de conhecimento para desenvolver seus estudos.

Nesta primeira década em que o tema foi explorado pela CI, destacam-se como núcleo de referência no país a UFSC, UnB, UDESC, UFBA e UFPB. Os autores mais citados, provavelmente aqueles que exerceram maior influência nas pesquisas elaboradas pelos citantes, foram: Jack Maness (EUA), Úrsula Blattmann (BR), Tim O'Reilly (IRL), Murilo Bastos da Cunha (BR), Fabiano Couto Corrêa da Silva (BR), Raquel Recuero (BR) e Manuel Castells (ESP).

Mesmo com uma produção científica relativamente recente (2007-2017), pode-se afirmar que a Ciência da Informação possui uma comunidade epistêmica em formação, com destaque para Henriette Gomes da UFBA e Alberto Calil Júnior da UNIRIO, que tem influenciado a produção nacional de outros pesquisadores ao mesmo tempo em que publicam os resultados de suas pesquisas.

Embora redes sociais seja o descritor preferido da comunidade discursiva da CI para designar os ambientes de interação mediados pelo computador/internet e, consequentemente, representar o domínio analisado, é possível afirmar que o termo mídias sociais, desde 2012, tem conquistado um espaço de destaque na produção científica da área, acompanhando o movimento já percebido na Comunicação Social desde o início dos anos 2000, fundamentado nos conceitos da Web 2.0 de Tim O’Reilly.

Considerando a informação como o modo como os sujeitos compartilham sua visão de mundo com os outros, é possível afirmar que a temática analisada se sustenta predominantemente no paradigma social da Ciência da Informação, descrito por Capurro e no paradigma tecnológico concebido pelo economista Giovanni Dosi, ao refletir sobre a imbricação dos conceitos de tecnologia, ciência e sistema econômico. Observou-se que além da influência de teóricos das áreas da 
Filosofia, Psicologia, História, Sociologia e Comunicação Social, os estudos analisados foram fundamentados em teóricos da Ciência da Informação, como Ranganathan, Lancaster, Buckland, Frohmann, Saracevic e Maness.

No Brasil, as pesquisas da Ciência da Informação sobre mídias sociais têm sido aplicadas nos mais diversos tipos de bibliotecas, com predileção pelo âmbito das bibliotecas universitárias. Quanto à classificação das pesquisas, observou-se que a abordagem mais usual foi a qualiquantitativa e, quantos aos objetivos, destacou-se a pesquisa exploratória. Em relação aos procedimentos técnicos, identificou-se o predomínio da pesquisa bibliográfica. A observação foi apontada como um dos instrumentos de coleta mais utilizado e para tratamento dos dados, a análise de conteúdo, de Bardin. Tornar público o percurso metodológico adotado para o desenvolvimento de uma pesquisa é um dos elementos que contribui para sua legitimação científica, passível de ser analisada, testada, ampliada e, até mesmo, contestada por outros pesquisadores. Neste contexto, curiosamente, metade das pesquisas analisadas não apresenta uma seção específica para descrição da metodologia de pesquisa adotada.

Na etapa de categorização do conteúdo dos artigos analisados, identificou-se que a maior parte pertence a categoria Uso aplicado em diversas áreas inerentes a uma biblioteca, como serviços de orientação, mediação e apropriação, marketing, promoção da leitura, disseminação da informação, automação e preservação digital. Também foram analisados estudos teóricos, de desenvolvimento (criação de tecnologias de informação e comunicação), sobre competência em informação e com viés político. Como brecha de conteúdo apresentam-se pesquisas que abordam as questões éticas no domínio analisado.

Tomando por base a organização sistemática do Tesauro do IBICT, é possível apontar a inserção do domínio analisado em áreas referenciais da CI, como: Organização do conhecimento e recuperação da Informação; Tecnologias da Informação e Comunicação; e Comunicação e Acesso à informação.

Por meio dos indicadores acima descritos, ao analisar a produção científica do país sobre mídias sociais e bibliotecas, identificou-se o comportamento e o desenvolvimento deste domínio na Ciência da Informação, em sua primeira década 
de existência. De maneira pragmática, foram indicados os novos léxicos que o representam para posterior análise e possível atualização de glossários e tesauros da área, acompanhando assim as tendências da sociedade atual.

\section{Referências}

BARO, E. E.; EBIAGBE, E. J.; GODFREY, V. Z. Web 2.0 tools usage: a comparative study of librarians in university libraries in Nigeria and South Africa. Library Hi Tech News, Ann Arbor, v. 30, n. 5, p. 10-20, 2013.

BRASIL. Coordenação de Aperfeiçoamento de Pessoal de Nível Superior. Tabela de áreas do conhecimento/avaliação. 2017.

BRASIL. Coordenação de Aperfeiçoamento de Pessoal de Nível Superior. Plataforma Sucupira. [2018].

CAMPOS, L. F. de B. Web 2.0, Biblioteca 2.0 e Ciência da Informação (I): um protótipo para disseminação seletiva de informação na web utilizando mashups e feeds RSS. In: ENCONTRO NACIONAL DE PESQUISA EM CIÊNCIA DA INFORMAÇÃO, 8., 2007, Salvador. Anais [...]. Salvador: ANCIB, 2007.

CAPURRO, R. Epistemologia e ciência da informação. In: ENCONTRO NACIONAL DE PESQUISA EM CIÊNCIA DA INFORMAÇÃO, 5., 2003, Belo Horizonte. Anais [...]. Belo Horizonte: UFMG, 2003.

DESENVOLVIMENTO humano para além das médias: 2017. Brasília: PNUD: IPEA: FJP, 2017.

FRANÇA, M. N.; CARVALHO, A. M. G. de. Análise da produção científica sobre mídias sociais e bibliotecas nos anais do ENANCIB. In: ENCONTRO NACIONAL DE PESQUISA EM CIÊNCIA DA INFORMAÇÃO, 19., 2018, Londrina. Anais [...]. Londrina: ANCIB, 2018.

FRANÇA, M. N.; CARVALHO, A. M. G. de; GRÁCIO, M. C. C. Presença da temática mídias sociais e bibliotecas na produção científica brasileira na ciência da informação: um estudo de análise de domínio. In: IRIGARY, Fernando et al. (Org.). Audiovisual, cidades, mobilidade, cidadania, jornalismo, mídia e tecnologia. Rosário: UNR Editora: Editorial de la Universidad Nacional de Rosário, 2018. p. 344-367.

HERRARA MORILLAS, J.; CASTILLO DÍAZ, A. Bibliotecas universitárias 2.0 el caso de España. Investigación Bibliotecológica, México, v. 25, n. 55, p. 175200, sept./dic. 2012. 
HJØRLAND, B. Domain analysis in Information Science: eleven approaches: traditional as well as innovative. Journal of Documentation, London, v. 58, n. 4, p. 422-462, 2002.

MUELLER, S. P. M. Bibliotecas e sociedade: evolução da interpretação de função e papeis da biblioteca. Revista da Escola de Biblioteconomia da UFMG, Belo Horizonte, v. 13, n. 1, p. 7-54, mar. 1984.

PESQUISA sobre o uso das tecnologias de informação e comunicação nos domicílios brasileiros [livro eletrônico]: TIC domicílios 2017. São Paulo: Comitê Gestor da Internet no Brasil, 2018.

PINHEIRO, L. V. R.; FERREZ, H. D. Tesauro brasileiro de ciência da informação. Rio de Janeiro: IBICT, 2014.

SANTOS, P. L. V. A. da C. et al. Mapeamento do termo tecnologia em periódicos da CI no escopo do GT8: informação e tecnologia. In: ENCONTRO NACIONAL DE CIÊNCIA DA INFORMAÇÃ̃O, 14., 2013, Florianópolis. Anais [...]. Florianópolis: UFSC, 2013. p. 1-19.

SHAFAWI, S.; HASSAN, B. User engagement with social media, implication on the library usage: A case of selected public and academic libraries in Malaysia.

Library Philosophy \& Practice, Lincoln, May 2018.

SILVA, E. L. da; MENEZES, E. M. Metodologia da pesquisa e elaboração da dissertação. 4. ed. rev. e atual. Florianópolis: UFSC, 2005.

SMIRAGLIA, R. P. ISKO 11's diverse bookshelf: an editorial. Knowledge Organization, Wurzburg, v. 38, n. 3, p. 179-186, Jan. 2011.

URBIZAGÁSTEGUI ALVARADO, R. Elitismo na literatura sobre a produtividade dos autores. Ciência da Informação, Brasília, v. 38, n. 2, p. 69-79, maio/ago. 2009.

\title{
Analysis of the scientific production on social media and libraries in Information Science journals in Brazil
}

\begin{abstract}
Social media is inserted in the much of society around the world in various segments, impacting the way of acting, thinking and relating to the subject. To libraries, as organizations responsible for providing access to information, to knowledge and learning, it is essential the monitoring of social changes and technological transformations, so they can fulfill their role in contemporary society. In this context, with this study aims to identify the characteristics of the Brazilian scientific literature regarding social media and libraries in order to monitor its evolution and point out trends. This is a descriptive study of qualitative-quantitative nature, based on the domain analysis, proposed by Hjørland. The research universe
\end{abstract}


consists of 54 articles published in national scientific journals of Information Science. It was found that the analyzed domain has been discussed in the community since 2007, especially in the context of University libraries. Most authors cited belong to Information Science, in collaboration with researchers from Social Communications and Sociology. The initial stage of formation of an epistemic community in Information Science was identified. Social networks has been the terminology commonly adopted by the researchers of the area to represent the communication environments mediated by the computer, though, the term social media has been featured in recent years. New lexicons in the analyzed domain have been identified for possible update of organization and representation schemes of knowledge produced in the country, in the field of Information Science.

Keywords: Social networks; Social media; Library; Domain analysis; Scientific production.

Recebido: 31/01/2019

Aceito: $12 / 04 / 2019$

${ }^{1}$ Este estudo corresponde a primeira etapa da pesquisa de doutorado em desenvolvimento na Linha 1 Informação e Tecnologia do Programa de Pós-Graduação em Ciência da Informação (PPGCI) da Universidade Estadual Paulista Júlio de Mesquita Filho (UNESP), campus Marília. No trabalho Presença da temática mídias sociais e bibliotecas na produção científica brasileira na Ciência da Informação: um estudo de análise de domínio, apresentado em outubro de 2017 no I Congresso Internacional de Mídia e Tecnologia (UNESP, Bauru, SP), publicado como capítulo de livro em 2018, identificou-se a necessidade de ampliar o escopo da pesquisa, visando alcançar melhor representação do domínio analisado na produção científica da Ciência da Informação, cujos resultados são apresentados na sequência.

${ }^{2}$ Conforme a versão antiga disponível em http://old.brapci.inf.br/. A partir do segundo semestre de 2018 foi disponibilizada uma versão Beta da BRAPCI, que trabalha com semântica, cujos algoritmos do sistema estão em fase de ajuste. A nova interface pode ser acessada pelo link: http://www.brapci.inf.br/index.php/res/.

3 Apesar de a temática mídia social ter surgido no início do século XXI, o período de coleta foi mais abrangente (todo período oferecido pela BRAPCI), a fim de se identificar o período exato (estudos históricos) em que o domínio analisado passou a ser objeto de estudo da Ciência da Informação no Brasil.

${ }^{4}$ Quatro artigos selecionados do periódico Tendências da Pesquisa Brasileira em Ciência da Informação não foram considerados pois apresentaram link inválido.

${ }^{5}$ Categorização adotada pela BRAPCI que nem sempre coincide com as seções definidas na política editorial do periódico analisado, por exemplo, um dos artigos selecionados foi incluído na categoria comunicação pela BRAPCI; no entanto, o periódico o identificou como um relato de pesquisa. Para análise dos resultados deste estudo, adotou-se a categorização da BRAPCI.

${ }^{6}$ Este procedimento também foi aplicado na seleção dos núcleos de pesquisa sobre o tema no país e dos autores citantes mais representativos.

${ }^{7}$ Universidade de Aveiro; Universidade Católica Portuguesa; Universidade de Évora.

${ }^{8}$ Universidad Complutense de Madrid; Universidad Carlos III de Madrid; Universidad de Murcia.

${ }^{9}$ University of Colorado at Boulder.

${ }^{10}$ Universidad Central "Marta Abreu" de Las Villas.

${ }^{11}$ Aligarh Muslim University.

${ }^{12}$ Como convergência digital; inteligência coletiva; cibercultura e/ou ciberespaço; biblioteca 2.0; serviços online ou serviços da Web; recursos da Web 2.0 e/ou plataformas Web 2.0; ferramentas colaborativas e/ou ferramentas da Web $2.0 \mathrm{ou}$, ainda, ferramentas de redes sociais. 